\title{
¿Auge o decadencia del Derecho Internacional Público?
}

\author{
Rise or decline of Public International Law?
}

\section{Aumento ou declínio do Direito Internacional Público?}

\author{
Ninoska Guillermina Hernández González \\ ninoskah@gmail.com \\ Universidad Nacional Experimental de la Fuerzas Armadas, Carabobo, Venezuela
}

Articulo recibido en febrero 2018; arbitrado en marzo 2018; aprobado en abril 2018 y publicado junio de 2018

\section{RESUMEN}

El propósito de este artículo, fue analizar el estatus actual del Derecho Internacional Público, (DIP) y el cumplimiento de las normas de conducta entre los diferentes sujetos de derecho, además de demostrar que no es el DIP el que se encuentra en decadencia, sino, que es la debacle de sus sujetos, los hombres que en momentos históricos son los encargados de articular y mover las piezas, en ese gran conglomerado denominado Comunidad Internacional. Se ubicó bajo paradigma cualitativo, de nivel descriptivo, utilizando como técnica para la obtención de la información, la revisión documental y la hermenéutica como actividad interpretativa de los hechos; de tal forma que, se compiló información relacionada al Derecho Internacional Público, comportamiento humano frente al uso, manejo y aplicación de las normas, para finalmente, realizar el respectivo análisis hermenéutico, relacionando las normas de conducta humana, con las normas del DIP. La investigación determinó, que no es el Derecho Internacional Público el que se encuentra en crisis o decadencia en el decir de sus negadores, sino por el contrario, en la medida que surgen contradicciones en la aplicación de las normas en la comunidad internacional, el DIP se fortalece, generando normas de control interno.

Palabras clave: Derecho Internacional Público; normas internacionales de conducta; tratados internacionales; acuerdos internacionales; organizaciones internacionales
ABSTRACT

The purpose of this article was to analyze the current status of Public International Law (DIP) and compliance with the rules of conduct between different subjects of law, in addition to demonstrating that it is not the DIP that is in decline, but, which is the debacle of its subjects, the men who in historical moments are in charge of articulating and moving the pieces, in this great conglomerate called the International Community. It was placed under a qualitative paradigm, of a descriptive level, using as a technique to obtain information, documentary review and hermeneutics as an interpretive activity of the facts; in such a way that information related to Public International Law was compiled, human behavior against the use, management and application of the norms, to finally, perform the respective hermeneutic analysis, relating the norms of human behavior, with the DIP norms. The investigation determined that it is not Public International Law that is in crisis or decadence in the words of its deniers, but on the contrary, as contradictions arise in the application of norms in the international community, the DIP it is strengthened, generating internal control standards. Keywords: Public International Law; International Standards of conduct; international deals; international agreements; international organizations.

Key words: Public International Law; international standards of conduct; international deals; international agreements; international organizations 
INTRODUCCIÓN

La importancia y relevancia de realizar una investigación acerca de la vigencia o decadencia del Derecho Internacional Público, parte de la iniciativa de la autora, en responder interrogantes planteadas por sus estudiantes en las aulas de clase, quienes cada vez se muestran escépticos en cuanto de la efectividad, en la aplicación efectiva de normativas que regulan las relaciones armónicas entre los sujetos del Derecho Internacional Público. En este sentido, como fiel seguidora y amante de las normas, necesarias para el mantenimiento del equilibrio social, se plantea como objetivo del estudio está dirigido al análisis del estatus actual del DIP y al cumplimiento de las normas de conducta entre los diferentes sujetos de derecho. La idea es demostrar que no es el DIP el que se encuentra en decadencia, sino por el contrario, es la debacle de sus sujetos o más aun, los hombres que en momentos históricos son los encargados de articular y mover la piezas, en ese gran conglomerado denominado Comunidad Internacional. De tal manera que, se destacarán como elementos resaltantes: El Derecho Internacional Público, su importancia, sujetos y actuaciones; la norma, como mandato de la conducta humana y como resultado, la subyacente disposición del DIP en relación a esta última. Ahora bien, de acuerdo a los planteamientos señalados, el estudio puramente documental, de nivel descriptivo de análisis hermenéutico.

\section{Importancia del problema}

La situación de crisis que hoy por hoy se presenta en la comunidad internacional, a diferentes niveles: político, económico, social, de valores, en todos sus sentidos, lo que permite percibir, bien sea por la mediática o por los datos presentados por organizaciones internacionales, como Amnistía Internacional o por órganos adscritos a las Naciones Unidas, un estado de convulsión internacional que no deja de generar preocupación a parte de la sociedad. Así, se presentan fuertes críticas, por la carente efectividad del Derecho Internacional $y$ quienes a ultranza le defienden, según fundamentos teóricos, basados en el desarrollo histórico de la sociedad, tras su necesidad de permanencia y desarrollo armónico. En este caso, no solo se presenta la importancia y relevancia del Derecho Internacional, sino que se hace una aproximación hacia la responsabilidad de la conducta humana en el manejo y cumplimiento de las normas, creadas por el hombre, para mantener el equilibrio armónico de la comunidad internacional, su cumplimiento y aplicación. Ello, llevaría que a futuro se apliquen las medidas correctivas dirigidas a que la conducta humana de quienes son sujetos del DIP, genere y refuerce, la aplicación explicita de las normas internacionales.

\section{MÉTODO}

Este estudio se ubica bajo paradigma cualitativo, de nivel descriptivo, utilizando como técnica para la obtención de la información, la revisión documental y la hermenéutica como actividad interpretativa de los hechos; de tal forma que, se compiló información relacionada al Derecho Internacional Público, comportamiento humano frente al uso, manejo y aplicación de las normas, para finalmente, realizar el respectivo análisis hermenéutico, relacionando las normas de conducta humana, con las normas del DIP.

La técnica usada fundamentalmente fue el análisis del discurso, y los resultados de este análisis se han incorporado en este artículo en sus diferentes partes, y ello permitió el plantear los resultados que se exponen a continuación, y nutren sustantivamente las conclusiones presentadas 


\section{Derecho Internacional Público}

Sobre la base de lo anteriormente indicado, se hará referencia a la definición de Derecho Internacional, como tal como lo plantea Verdross, (1963) como el conjunto de normas reconocidas como obligatorias por las naciones y los Estados que reflejan los principios y valores del derecho natural, y cuya eficacia depende siempre de un imperio democrático.

Ello significa que el Derecho Internacional, tal como lo plantea Rousseuau, (1966). le da primacía a la norma para la eficiencia en las relaciones entre los Estados y los restantes sujetos de derecho. En consecuencia, es importante señalar a manera de recordatorio que el Derecho Internacional comienza su auge a partir del siglo XVI, a partir de la aparición los primeros estados nacionales europeos; pero, su desarrollo como tal, es iniciado el Siglo XX, tras el desarrollo del concepto de soberanía. Asimismo, de manera específica, el Derecho Internacional Público, definido por autores como, Paul Fauchille, Antonio Truyol y Serra, Bonfils, Carlos Calvo, Manuel Francisco Mármol, Kelsen, Korovín, es definido como el conjunto de normas o principios que regulan las relaciones jurídicas de los estados entre sí, lo cual integran normas establecidas por vía consuetudinaria para regular las relaciones entre los estados, lo que genera obligaciones, responsabilidades y derechos para todos los estados.

Sin embargo, el nacimiento de las organizaciones internacionales y el desarrollo del Derecho Internacional Humanitario, hace que en la actualidad, el concepto del Derecho internacional Público presente cierta variación con respecto a lo anteriormente indicado, anexando a la definición clásica del DIP (relaciones entre los estados), la de otros sujetos de derecho internacional como son: Los organismos internacionales, grupos beligerantes; territorios fideicometidos,
Comité Internacional de la Cruz Roja, la Santa Sede (Vaticano), organizaciones internacionales, los individuos como destinatarios de las normas, entre otras. De tal manera, el Derecho Internacional público es, el ordenamiento jurídico de la Comunidad Internacional que regula el comportamiento de los Estados y otros sujetos internacionales, en sus competencias propias y relaciones mutuas, sobre la base de valores comunes, coadyuvantes de la paz y cooperación, a través normas surgidas del contrato social internacional; lo cual, es admitido por toda la doctrina.

Actualmente, la función del Derecho Internacional va más allá de regular las relaciones entre los estados, su función ha llegado al campo interinstitucional, con el nacimiento de las organizaciones internacionales y organismos especializados que fueron creados con la finalidad de establecer la cooperación política, económica $\mathrm{y}$ administrativa internacional y asimismo por la conciencia que han tomado los estados de la necesidad de una sociedad mundial organizada. Relación entre el Derecho Internacional Público y el Derecho Interno de los estados. Se refiere fundamentalmente al estudio del ámbito de aplicación y al problema de las relaciones existentes entre el Derecho Internacional y el derecho Interno, tomando en cuenta que ambos constituyen órdenes coercitivos.

Según Monrroy (2002), la responsabilidad internacional surge cuando un Estado $\mathrm{u}$ otro sujeto de derecho internacional, ya sea por acción o por omisión, viola una obligación de derecho internacional. En el caso de la acción se trata de la infracción de una prohibición jurídica internacional, y en el caso de la omisión, del no cumplimiento de un imperativo jurídico internacional. Para los seguidores de esta corriente, dentro del Estado solamente puede regir el Derecho Interno, ya que el Derecho Internacional rige únicamente para las relaciones entre los 
Estados, debiendo transformarse en derecho nacional para que tenga eficacia.

En este orden de ideas, para Sáez (2014), se plantean dos teorías que explican las relaciones del Derecho Internacional y el Derecho Interno: El Dualismo y el Monismo, que tratan de solucionar el problema consistente. Así, el Dualismo parte de la idea de que el Derecho Internacional y el Derecho interno de los estados constituyen dos sistemas jurídicos independientes, separados ( $\sin$ formar parte el uno del otro) las cuales nunca llegan a fundirse y por lo tanto no debe haber un conflicto entre ellos, ya que ambos ordenamientos jurídicos poseen características diferentes: Poseen fuentes diferentes y por lo tanto, contenidos distintos que el Derecho Interno procede de la voluntad unilateral del estado, el DIP de la voluntad común de varios estados, presentan diversidad de los sujetos, los destinatarios son diferentes. En el derecho interno las normas van dirigidas a los individuos en sus relaciones recíprocas, ya sea entre ellas mismas o entre el individuo y el Estado, y en el D.I.P van dirigidas a los Estados, a las Organizaciones Internacionales y demás sujetos del derecho; además, las leyes nacionales conservan su fuerza obligatoria en el orden interno aun cuando estén en oposición a las reglas del DIP.

En ese sentido, Rousseau, quién participó de esta teoría, consideró que el "Derecho Internacional y el Interno eran sistemas de derecho igualmente válidos, pero de ninguna manera podían confundirse". Triepel y Anzilotti, también representantes de esta posición, afirman que, aunque existe alguna relación entre los dos ordenamientos jurídicos, se trata de dos sistemas separados, no siendo pertinente proferir de Normas Internacionales que sean producto de normas internas, ni viceversa, ni influir las una sobre las otras en su respectivo valor obligatorio. Para los seguidores de esta corriente, dentro del Estado solamente puede regir el Derecho
Interno, ya que el Derecho Internacional rige únicamente para las relaciones entre los Estados, debiendo transformarse en derecho nacional para que tenga eficacia. De igual forma, para Sáez, Paula y Jorquera Gabriel, ob. cit., la teoría dualista fundada por los ius publicistas Triepel y Anzilotti, el Derecho Internacional y el Derecho Interno son dos ordenamientos jurídicos aislados, ya sea por sus diferentes destinatarios como por su ámbito de validez. La producción de las normas del Derecho Internacional es a partir de un procedimiento internacional y la obligatoriedad de su cumplimiento recae sobre los Estados, en cambio el alcance del Derecho Interno no es el mismo.

De la misma forma, las normas internas opuestas al Derecho Internacional no carecen de obligatoriedad, pues los tribunales están en la obligación de aplicar las leyes aun cuando exista infracción al Derecho Internacional, lo que tiene su fundamento en que los tribunales son órganos de un determinado ordenamiento jurídico estatal y como tales, han de aplicar las normas que el derecho propio les prescribe. Sin embargo, estas normas de Derecho Internacional se aplicarán en la medida de lo posible. Para los seguidores de la teoría monista, el Derecho Interno y el Derecho Internacional forman parte de un único sistema. Dentro de esta corriente existen varias posiciones, entre ellas la asumida por Kelsen quien consideraba que toda norma o acto contrario al ordenamiento jurídico internacional era nulo. Si bien esta vertiente de la teoría monista no resulta suficiente por el hecho que no toda norma contraria al Derecho Internacional es nula, la teoría dualista de la completa separación entre tales derechos, tampoco es suficiente, en tanto la norma contraria al Derecho Internacional es interna y provisional. El control jurídicointernacional puede recaer sobre el procedimiento legislativo estatal, de ahí que el Derecho Interno estará limitado por el Derecho Internacional. 
Ante esta disyuntiva surge el "monismo moderado o estructurado" defendido por Verdross, quien destaca, que aun persistiendo la independencia entre Derecho Interno y Derecho Internacional, cada uno de ellos goza de su propia individualidad, de manera que la norma interna no es nula pero puede generar responsabilidad jurídica internacional del Estado cuando contravenga las normas del Derecho Internacional Público. En la contemporaneidad resulta mejor acogida la tesis del monismo moderado, lo que tiene como fundamento el rol que desempeña el Derecho Internacional Público en la ordenación de las relaciones internacionales.

\section{Las normas de conducta como mandato del Derecho Internacional Público}

Siendo la base y esencias de la investigación realizada es, conocer, si realmente el Derecho Internacional Público se encuentra en decadencia, si por el contrario son las normas de conducta las que actúan contrariamente a los principios y valores en el hacer del mismo o si es la desviación contraria de la conducta humana la actuante en la desviación de tales principios y valores. Sobre lo indicado, se tomó la investigación realizada por Abbott (2005), en la que desarrolla una aproximación teórica de la conducta humana, presentando los diferentes tipos de normas, hasta llegar a las normas jurídicas. En este sentido, indica el autor que la norma se define usualmente, como "un mandato de la conducta humana", definición a la que suele agregársele algo más, dependiendo, por lo general, del tipo de norma específica de que se trate. Ahora bien, sabiendo lo que es una prescripción (este tipo de mensaje que pretende influir en la conducta de alguien), las normas se ubican dentro de la clase más fuerte de prescripciones, precisamente por lo que ocurre en caso de desobediencia: la sanción, elemento fundamental de cualquier norma. Es allí, donde se asienta la posición autora, dirigida hacia la defensa del DIP, afectado en su totalidad, por la desobediencia e incumplimiento humano. De tal manera, el autor señalado, se plantea las siguientes interrogantes, planteadas por varios autores: ¿para qué existen las normas? ¿Se puede vivir sin ellas? ¿Son, una negación de la libertad?, respondiéndose que no extrañaría que algunos concluyan que las normas quitan libertad, esclavizando al hombre. Ello, se presentaría como un absurdo análisis debido a que las normas son necesarias para regular la conducta humana, la cual debe encausarse, porque de lo contrario, la sociedad estaría en una completa anarquía.

Contrariamente, continúa, la conducta de los animales es instintiva, programada y prestablecida, lo cual se diferencia de la conducta humana debido que el hombre posee inteligencia o razón para conocer el mundo teniendo plena conciencia de su existencia. De esta manera, ante los diferentes acontecimientos y estímulos de la vida, no se encuentra atrapado por las reglas, no es un prisionero de sus instintos, sino que él mismo decide qué hacer y qué no; sus posibilidades futuras son un abanico abierto de posibilidades. De este modo, ninguna vida está programada de antemano, en cada caso es, por decirlo de algún modo, un gran signo de interrogación, motivo por el cual se es artífices, siendo responsables cada quien de su vida. De tal forma, esgrime el señalado autor, que el hombre, al ser libre, al tener este "pluridireccionalidad", puede actuar de muchas maneras; no infinitas, porque su naturaleza es finita, pero sí muchas. Otra particularidad común a todos los seres vivos, es la inmanencia, la es la consecuencia que sobre el propio ser vivo tienen sus acciones, de todo tipo: si come, es él mismo y no otro, el que se alimenta; o en nuestro caso, si pensamos, es una acción que nos afecta a nosotros. En el fondo, como somos agente y paciente al mismo tiempo, la inmanencia se vincula al simple hecho de ser nosotros, en primer lugar, los destinatarios de nuestros 
actos: aun cuando actúe para otro u otros, son yo mismo el que actúo, y esa actuación repercute en mí mismo, lo quiera o no. La inmanencia, por tanto, quiere decir que el hombre es receptor de sus actos, auto influyendo en sus acciones. Así que, todas sus vivencias repercuten en él, realimentándose de ellas, lo cual ha sido demostrado por la sicología. Igualmente, recibe afectaciones del entorno, el ambiente o hábitat en el que se desenvuelve, no siendo indiferente al mismo. Contrariamente, este entorno tiene influencia decisiva en forma de ser humana, en o en su personalidad; de allí, que la historia de cada uno sea absoluta y totalmente única, porque nadie tendrá las vivencias, propias o ajenas, la historia de cada uno es irrepetible; esto, conlleva que la noción misma de naturaleza implica la idea de imperfección, de limitación.

\section{Estructura de las normas de conducta}

Tal como lo plantea Valencia (2008) una norma tiene dos aspectos o partes fundamentales: una primera parte está constituida por lo que dice la norma, por su mensaje, o según se ha visto, por lo que ella prescribe. Una segunda parte está constituida por la sanción, esto es, la consecuencia que deviene por el incumplimiento de lo que ella prescribe. En tal sentido, toda norma tiene como primer aspecto, su prescripción, además, tiene un mensaje, un contenido que se dirige a sujetos, a destinatarios determinados o indeterminados. Las prescripciones, pueden ser muchas y muy variadas; sin embargo, y pese a sostener lo contrario por lo común las varias manifestaciones del positivismo jurídico, el contenido de una norma no puede ser cualquiera; es decir, aun reconociendo su enorme vastedad, hay límites, fronteras para el contenido normativo. Asimismo, señala que hay limitaciones, por lo que los hombres pueden hacer unas y otras no. Ello, no es otra cosa que la regla de que "el actuar sigue al ser", o visto desde otra perspectiva, de que "nadie puede dar lo que no tiene", o "el efecto no puede ser más que la causa". Sea como fuere, lo importante es que hay todo un ámbito de acciones posibles, que están al alcance humano. No importa cuánto se avance en este campo; lo importante es que siempre existirá una frontera, un límite, más allá del cual, no se puede actuar.

De este modo, se puede concluir que la propia naturaleza humana, estructura o forma de ser, enmarca las posibilidades normativas, o si se prefiere, las prescripciones posibles tienen un límite. Por tanto, sólo es dentro de estas acciones posibles (que en el fondo, es el campo que coincide con el de la libertad humana) donde las normas, como pautas de conducta, tienen algo que decir. De ahí que se diga que su contenido debe referirse a las acciones posibles, y no a las imposibles o las necesarias. Ahora bien, la norma, adopta varias formas, unas más intensas que otras. Muchas veces, son sólo formas distintas de pretender un mismo objetivo, un mismo fin, pero se adopta una $u$ otra, por razones tácticas, o si se prefiere, para intentar tener mayor éxito. Usualmente, se distinguen tres modalidades deónticas: los mandatos, las prohibiciones y las permisiones. En el caso del mandato, se trata, como se dice generalmente, de una "obligación de hacer": el sujeto está en la necesidad de comportarse de tal o cual manera, a menos que quiera sufrir las consecuencias de la sanción (que veremos pronto). Por el contrario, si está frente a una prohibición, se encuentra ante una "obligación de no hacer o de abstenerse". Por último, si está ante un permiso (una "permisión", como se le llama usualmente), tiene la facultad de obrar o no. Por lo común, las permisiones se dividen entre "permisiones positivas" (que dan la facultad de obrar, la posibilidad de hacer algo), y en "permisiones negativas" (que dan la facultad de no hacer o de omitir).

Como puede destacarse, hay una estrecha relación entre mandatos y prohibiciones, porque en ambos se habla de "obligación". En 
un caso será una obligación de hacer (también llamada "obligación positiva") y en el otro, de no hacer, llamada "obligación negativa". Lo importante es que en ambos casos es una obligación, o sea, una conducta que el sujeto debe hacer, so pena de verse expuesto a las consecuencias de la sanción. 0 si se prefiere, que tienen implícita una amenaza, un mal, un perjuicio, y por lo mismo, cuya ejecución no queda sólo entregada a la voluntad del destinatario, como en el caso de un ruego o consejo.

Más aún en realidad, mandato y prohibición son dos caras de la misma medalla, porque lo que se manda por un lado, lleva implícito la prohibición de las restantes conductas posibles (si digo "dirección obligada", estoy señalando implícitamente, que las demás direcciones posibles se encuentran prohibidas o vedadas). A su vez, puede ocurrir que existen una o varias prohibiciones, que dejen sólo una vía posible para actuar; en este caso, en el fondo, se nos está mandando -ordenando- seguir esa única vía que queda, aun cuando no se observe. Pero también hay una estrecha relación entre mandatos (positivos o negativos) y permisos. En efecto, si se nos prohíbe algo, es muy probable que si queda más de una posibilidad, se nos esté permitiendo optar por alguna de ellas. Por el contrario, si se nos está ordenando una conducta, resulta claro que no puedo optar por realizar esa conducta o no (a menos que quiera enfrentar las consecuencias de la sanción, puesto que en el fondo, y como se ha dicho, toda norma lleva implícita la posibilidad de su incumplimiento), ni menos, optar por otra de las conductas posibles. Con todo, se presenta un problema respecto de las normas permisivas, no importa si son positivas o negativas. En efecto, si se recuerda lo dicho a propósito de las prescripciones, se dijo que las normas se ubicaban dentro de la clase más fuerte de ellas, la de las órdenes o mandatos. De ahí que el seguir o no su mensaje, no quede entregado únicamente al capricho del destinatario, porque existe una posibilidad de daño en caso de desobediencia. Ahora bien, ¿no resulta algo contradictorio haber dicho esto y señalar ahora que dentro de las normas (esto es, del tipo más fuerte de prescripciones) existan "permisos"? Desde el momento en que se habla de "permisos", se subentiende que queda al capricho o voluntad del destinatario seguirlos o no; en el fondo, podrían, a primera vista, asimilarse a un consejo o incluso a un ruego.

\section{Clases de normas}

Puesto que el actuar del hombre puede ser inmenso, resulta evidente que existen varias clases de normas; su riqueza es demasiado amplia para que sus posibilidades se agoten en una sola clase de normas, de pautas de conducta.

Existen muchas clases de normas, pero usualmente, se han distinguido cuatro: normas religiosas, normas morales, normas de uso o trato social, y normas jurídicas. Para algunos autores, estas normas constituyen auténticos "compartimentos estancos", esto es, no se tocan en cuanto a sus prescripciones, y son por ello, independientes.

Con todo, puede ocurrir que pautas de una clase de normas, se transformen en otro tipo de pauta de conducta con el tiempo, o que lo que antes pertenecía a una de ellas, pase a formar parte de otra. Para otros autores, por el contrario, aun existiendo ámbitos exclusivos de unas y otras clases de normas, existen varios puntos de contacto, esto es, resulta perfectamente posible que las mismas conductas sean reguladas a la vez por varias clases de normas, aun cuando cada una lo haga desde una perspectiva distinta y persiguiendo fines diferentes. Esta es la postura que se sigue aquí, puesto que, por ejemplo, existen varias conductas que son reguladas por normas diferentes, cada una desde su ángulo particular. 


\section{Normas religiosas}

Las normas religiosas son aquellas que regulan la relación del hombre con Dios. Como tales, pretenden lograr la amistad entre Dios y cada uno de nosotros, de manera personal e íntima. Por lo mismo, como cualquier amistad con otra persona, se trata de una relación que debe ser querida, buscada, o si se prefiere, que no puede imponerse por la fuerza, tal como no existe la amistad o el amor forzados. De ahí que el hombre pueda, libremente, no seguir estas normas (puesto que toda norma lleva implícita la posibilidad de su incumplimiento, y la norma religiosa no es la excepción), e incluso comportarse como si ellas no existieran, lo cual no significa que las consecuencias de ello queden también a su arbitrio, como se verá.

\section{Las normas de uso o trato social}

Las normas de uso o trato social, también llamadas de la educación, de las buenas maneras o de la "etiqueta" (aun cuando esta última nomenclatura resulte algo anticuada), son aquellas normas o prescripciones que regulan el modo correcto de comportarse ante otros, a fin de hacer más agradable o tolerable la convivencia. Son sin duda las normas menos importantes de las que se analizan aquí, pero no sólo siempre existe (o si se prefiere, nunca pueden faltar), sino que tienen precisamente el mérito de pretender hacer más armónica la convivencia. Son por ello, normas eminentemente sociales, esto es, que requieren de la presencia de más de un sujeto (al contrario de algunas normas morales, según se verá, que regulan también la relación con uno mismo). Son así, bilaterales (tienen dos lados o partes), y son una evidente muestra del carácter social del ser humano.

Como se ha dicho, siempre hay estas normas de uso o trato social. Desde el momento en que necesariamente debemos relacionarnos con mucha gente a diario, existen modos mejores y peores de hacerlo. Lo importante, es que siempre surgirán estas normas, que nos indicarán cómo comportarnos en tal o cual circunstancia, dependiendo de la situación y de nuestro papel o rol dentro del todo social. De este modo, el contenido de estas normas es variadísimo: van desde la regulación del modo de comer, al de vestirse o de hablar, por decir sólo los casos más evidentes.

\section{Las normas jurídicas}

Las normas jurídicas parten de la regulación que tiene el hombre de su libertad; de tal manera, que se encuentran numerosas definiciones. Lo básico es que las mismas se dirigen a regular su conducta social. Así que, las normas jurídicas regulan varias cosas: regulan la actividad de los gobernados entre sí, donde el papel del derecho es esencial para mantener la paz social; pero también regula la actividad del gobernante, en cuanto a cuáles órganos existen y qué hacen, fundamentalmente, porque su accionar tendrá un efecto directo en los gobernados; por último, también es posible hoy que el Derecho regule la actividad de los gobernados en cuanto influya sobre los gobernantes, como ocurre en un sistema democrático. De este modo, el derecho, en este caso entendido como normas jurídicas, se encuentran inmersas en todas las relaciones humanas, de forma tal que cumplen un papel fundamental para el mantenimiento de la sociedad, en todos sus niveles: entre los receptores respecto de los emisores de las mismas.

\section{DISCUSIÓN}

Para los negadores totales del DIP todas las relaciones internacionales (y dentro de ellas las relaciones jurídicas internacionales), descansan única y exclusivamente en el principio de la política de fuerza. Para Spinosa, aparece como mera función de un campo internacional de fuerzas en constante devenir, que vez de regular las relaciones internacionales de poder, Larsson sostiene que no puede hablarse de una autoridad 
soberana en las relaciones internacionales porque en ellas reina la enemistad y el estado de guerra latente. Por otra parte, Seydel sostiene que como falta en la comunidad internacional una voluntad soberana superior, no hay sitio en ella para un Derecho Internacional Público propiamente dicho, no existe un Estado mundial y por consiguiente, no cabe hablar razonablemente de un verdadero DIP. Asimismo, hay quienes afirman que la vigencia intermitente, siendo normas jurídicas; y finalmente, quienes niegan el carácter jurídico de las normas, cuya obligatoriedad y normatividad son generalmente admitidas pareciendo como simples reflejos de las modificaciones de poder.

De igual manera, hay quienes plantean el hecho acerca de la calidad de conflictos posteriores a la II Guerra Mundial, que no se han podido ni evitar ni detener por organizaciones garantes de la paz mundial, tal como la ONU. Al respecto, Patiño (2005) sostiene que, el orden internacional de la posguerra 1945 hasta 1991, se presenta con dos caras; por un lado su cara formal, que fue producto de la creación de las Naciones Unidas, donde la carta fundacional cumple el papel de formulación constitucional y diseño institucional para el gobierno mundial supraestatal. Esta cara formal del orden internacional es la recepción directa de las influencias del ex presidente Woodrow Wilson en la creación de la Liga de Naciones. La cara informal del orden internacional fue el producto de la confrontación y apareció en el contexto de la contingencia en la relación soviético-norteamericana. Esta cara informal ha sido conocida como la guerra fría; y tiene un doble aspecto, es tanto un mecanismo de competencia como uno de cooperación entre Estados Unidos y la Unión Soviética."

Contrariamente a lo indicado previamente, hay quienes le defienden, e indican que es la falta de juez que aplique las normas internacionales, lo que se disminuye, porque el Derecho es anterior al juez, que no lo estructura, sino que lo aplica. Asimismo, la falta de sanción siempre ocurrió antes y es la Organización de Naciones Unidas (O.N.U.), la que establece un régimen de sanciones. Igualmente, a los críticos que señalan como caracterizantes del DIP de hoy, la ejecución coactiva del fallo judicial, se destaca la existencia de una jurisdicción internacional en la corte de Justicia Internacional, en la corte de mediación, arbitraje entre otros. De tal forma que, el Derecho Internacional Público se dirige a los estados como unidad de decisión y actuación, en tanto que el Derecho Interno hace a su vez amplia referencias a normas del Derecho Internacional Público.

En el mismo orden de ideas, Peña (2010) destaca que el Derecho Internacional no está en decadencia, sino más bien, quien se encuentra en crisis, es el Sistema normativo internacional; señala además que el DIP es, en un concepto un sistema legal completo que cubre todas los aspectos de las relaciones entre Estados... dentro de los Estados mismos $\mathrm{y}$ sus unidades federales, entre Estados y personas, entre personas de diferentes Estados, entre Estados y corporaciones multinacionales y entre las organizaciones internacionales y los Estados miembro de las mismas. Sin embargo, de ello no es posible comprender muchas veces la regulación jurídica internacional y pública, un detalle significativo olvidado inclusive por juristas.

Esta regulación abarca de manera completa muchas áreas: guerra, paz, derechos humanos, medio ambiente, economía, tecnología y así otros tópicos de no menor importancia. Este sistema legal se enmarca dentro de lo que es el DIP, pero es demasiadas veces olvidado, sus obligaciones son incumplidas, con lo que se suele entender que existe una "idea general" de falta de obligatoriedad como una característica sostenida (hecha presente por muchos autores de DIP en el siglo XIX). Sin embargo, el que no haya respeto por las normas de DIP no 
debe movernos a pensar que existe falta o inexistencia de las mismas. A ello, debe agregarse, la conducta de quien se encarga de aplicar las normas, quien debe poseer una formación en valores para tal fin.

\section{CONCLUSIONES}

De acuerdo a los señalamientos descritos, queda completamente demostrado, que no es el Derecho Internacional Público el que se encuentra en crisis o decadencia en el decir de sus negadores, sino por el contrario, en la medida que surgen contradicciones en la aplicación de las normas en la comunidad internacional, el DIP se fortalece, generando normas de control interno.

Sin embargo, queda abierta la discusión acerca de la responsabilidad de la conducta del hombre en el manejo y aplicación de las normas, en lo cual, se entraría en un profundo análisis ontológico y epistemológico del hombre, como principal actor activo $\mathrm{y}$ actuante en todos los sujetos de Derecho Internacional Público. Igualmente, queda abierta una futura investigación, relacionando la conducta humana, DIP e intereses geopolíticos de las grandes potencias internacionales para crear y mantener áreas de influencias.

En este sentido, es importante destacar, que posterior a la culminación de la II Guerra Mundial en 1945, lo cual da origen a la creación de las Naciones Unidas, cuyo fundamental objetivo es la preservación de la de la paz mundial, no lográndolo la Sociedad de Naciones, ya que no pudo evitar las dos guerras mundiales; pero, lo que llama a la meditación y análisis es que desde 1948 a la actualidad, se han suscitado 28 guerras y que según informe 2017-2018 de Amnistía Internacional (2018), aún se mantienen activas: Afganistán, Guerra Civil Yemení (incluida la Intervención militar en Yemen de 2015, Guerra Civil Siria con intervención de USA y Rusia, Insurgencia Iraquí y Libia, entre otras.
Igualmente, el mismo informe señala que durante 2017, millones de personas de todo el mundo probaron los frutos amargos del auge de la política de demonización. Sus consecuencias más extremas quedaron de manifiesto en la atroz campaña militar de limpieza étnica emprendida contra el pueblo Rohingya en Myanmar.

En cuestión de semanas causó el éxodo de alrededor de 655.000 personas a la vecina Bangladesh, generando la crisis de refugiados más vertiginosa de 2017. Al concluir el año, las perspectivas de futuro de quienes huían seguían siendo muy poco claras, y la persistente inacción de los líderes del mundo a la hora de ofrecer soluciones reales para las personas refugiadas dejaba escaso margen para el optimismo.

Las reflexiones indicadas a lo largo de la investigación pueden modernamente sustentarse en lo planteado por Sorensen (2016), quien sostiene que, el realismo tienen una visión pesimista de la naturaleza humana, considera que el hombre, se convierte en un enemigo para sus semejantes $y$ se hace necesario por ello constituir un Estado que lo defienda de sus ataques y a su vez imponga el orden, considera que las relaciones internacionales son en su conjunto conflictivas y que en la mayoría de los casos se tiende a resolver los problemas políticos a través de las guerras, hay un elemento importante en lo que plantean estos dos autores y es que son escépticos al creer que puede darse un progreso en la política internacional comparado o mejor igualado a la política interna de los Estados, es decir, no creen que haya progreso interno y que esto a su vez repercuta necesariamente en el progreso internacional.

Bajo el mismo enfoque, Del Arenal, (2005) señala que hoy, en la sociedad internacional de nuestros días, ese consenso, que permitió el funcionamiento del equilibrio de poder hasta el siglo $\mathrm{XX}$, ya no existe, dado que los cambios estructurales que se han 
producido en la sociedad internacional impiden su correcto funcionamiento. Sobre todo, el hecho de que han desaparecido las condiciones en que se sustenta, en especial la sustitución de un cierto número de grandes potencias por dos superpotencias, hace que sea inefectivo para el mantenimiento del orden internacional.

Por tanto, es sumamente importante, reflexionar y dirigir a la sociedad más hacia la formación de hombres, cuya conducta en el ámbito de aplicación del Derecho Internacional Público se base en el espíritu y principios que lo sustentan, haciéndose necesario mantener el equilibrio en todas las vertientes que conforman la comunidad internacional; asimismo, ir a la raíz de su objeto y sus principios, como los conceptos extrajurídicos de paz, estado de derecho y de Justicia.

Abbott, M. republicanismo un acercamiento contemporáneo. Medellín: Universidad Pontificia Bolivariana
Amnistía Internacional (2018). Informe Anual 2017-2018. , Easton Street, London WC1X 0DW Reino Unido

Del Arenal, C. (2005). Introducción a las relaciones internacionales. Madrid: Tecnos.

Monrroy, M. (2002). Derecho Internacional Público. Editorial Temis S. A. Bogotá Colombia

Patiño, C. (2005). El origen del poder en Occidente. Estado, Guerra y Orden internacional. Bogotá: Siglo del Hombre Editores. (2006). Guerra de Religiones. Transformaciones sociales en el siglo XXI. Bogotá: Siglo del hombre editores.

Peña, S. (2010). ¿El Derecho internacional en Crisis? UMAN, México

Rousseuau, C. (1966). Derecho Internacional Público. ·era edición, ARIEL. Barcelona, España

Sáez, P. (2014). Conflicto de normas de derecho internacional con normas de derecho interno. Presentación Prezi

Sorensen, J. (2016). Introduction to International Relations, thories and approaches. Sixth edition, Oxford

Verdross, A. (1963) Derecho Internacional Público, 5ta Edición. Madrid

Valencia, H. (2008). Derecho Internacional Público. Bogotá: Universidad Pontificia Bolivariana 